\title{
A Protein Kinase A-Ezrin Complex Regulates Connexin 43 Gap Junction Communication in Liver Epithelial Cells
}

\author{
Aleksandra Dukic ${ }^{1,2}$, Linda Hofstad Haugen ${ }^{5}$, Guillaume Pidoux ${ }^{6}$, Edward Leithe ${ }^{7}$, Oddmund Bakke ${ }^{5}$ \& \\ Kjetil Taskén ${ }^{1,2,3,4^{*}}$
}

${ }^{1}$ Centre for Molecular Medicine Norway, Nordic EMBL Partnership, University of Oslo and Oslo University Hospital, Oslo, Norway. ${ }^{2}$ Biotechnology Centre, University of Oslo, Oslo, Norway. ${ }^{3}$ K.G. Jebsen Inflammation Research Centre, University of Oslo, Oslo, Norway. ${ }^{4}$ Department of Infectious Diseases, Oslo University Hospital, Oslo, Norway. ${ }^{5}$ Department of Biosciences, Centre for Immune Regulation, University of Oslo, Oslo, Norway. ${ }^{6}$ UMR-S 1180, Inserm, Univ. Paris-Sud, Université ParisSaclay, Châtenay-Malabry, France. ${ }^{7}$ Department of Molecular Oncology, Institute for Cancer Research, Oslo University Hospital HE - Norwegian Radium Hospital, Oslo, Norway.

*Corresponding author at: Centre for Molecular Medicine Norway, Nordic EMBL Partnership, University of Oslo, P.O. Box 1137 Blindern, N-0318 Oslo, Norway, Tel: +47 22840505, Fax: +47 22840506, E-mail: kjetil.tasken@ncmm.uio.no

Highlights

- Ezrin is a membrane-anchored AKAP in liver epithelial cells

- Ezrin associates with Cx43 bringing PKA in proximity to $C_{x 43}$ in liver epithelial cells

- Gap junction communication is regulated by anchored PKA phosphorylation in liver epithelial cells 


\begin{abstract}
Communication between adjacent cells can occur via gap junctions (GJ) composed of connexin (Cx) hexamers that allow passage of small molecules. One of the most widely and highly expressed Cxs in human tissues is $\mathrm{Cx} 43$, shown to be regulated through phosphorylation by several kinases including PKA. Ezrin is a membrane associated protein that can serve as an A kinase anchoring protein (AKAP) and hold an anchored pool of PKA. Here, we used the liver epithelial cell line IAR20, which expresses Cx43 as the predominant GJ protein, to test the hypothesis that Ezrin may associate with $\mathrm{Cx} 43$ in cell types that form stable GJs and serve as an AKAP. Our biochemical and proteomics data indicate that Ezrin associates with $\mathrm{Cx} 43$ in epithelial cells. Analyses by confocal immunofluorescence microscopy and proximity ligation assays demonstrate that Ezrin and $\mathrm{Cx} 43$ co-localize, together with zonula occludens-1 (ZO-1) and PKA Rl $\alpha$ and RIl $\alpha$, at the cell membrane. Quantitative gap-FRAP experiments show increased GJ intercellular communication after cAMP stimulation. Moreover, loading of cells with the $\mathrm{Ht} 31$ peptide that displaces both PKA RI $\alpha$ and RIl $\alpha$ from the AKAP or a peptide that disrupts the Cx43-Ezrin interaction reverts the effect and reduces the level of communication, supporting the hypothesis that in IAR20 cells Ezrin associates with Cx43 (in complex with ZO-1) which places PKA in proximity to $\mathrm{Cx} 43$, enabling its phosphorylation and GJ opening.
\end{abstract}

\title{
Keywords
}

Cell signaling, cAMP, PKA, Ezrin, Cx43, gap junctions

\begin{abstract}
Abbreviations
GJ, gap junction; Cx, connexin; GJIC, GJ intercellular communication; PKA, cAMP-dependent protein kinase; AKAP, A-kinase anchoring protein; AKB, A kinase binding domain; ERM, ezrin, radixin, moesin; hCG, human chorion gonadotropin; ZO-1, zonula occludens-1; C, catalytic subunit; PLA, proximity ligation assay; PKI, protein kinase inhibitor; TPA, 12-O-tetradecanoylphorbol-13-acetate; EGF, epidermal growth factor; $k$, transfer rate constant; WGA, wheat germ agglutinin; gap-FRAP, gapFluorescence Recovery After Photobleaching.
\end{abstract}

\section{Introduction}

Gap junctions (GJs) are channels composed of integral membrane proteins termed connexins (Cxs), which form hexameric pores that transverse the cell membrane of two adjacent cells and allow the 
passage of fluid, ions and molecules smaller than approximately $1 \mathrm{kDa}$ between cells [1]. The $\mathrm{Cx}$ family includes 21 members in humans, and are numbered according to their molecular weight in kilodaltons [2]. Cx43 is the most widely expressed and predominant Cx in many primary cell types as well as in a number of cell lines. GJ intercellular communication (GJIC) plays important roles in development, cell growth control, as well as metabolic homeostasis and synchronized physiological functions of cells [3]. Aberrant GJIC has been linked to several human diseases, including cancer [4, 5]. Phosphorylation plays an important role in the acute regulation of GJ channels. The C-terminus of Cx43 contains several putative phosphorylation sites that are prone to phosphorylation by many kinases, including CAMP-dependent protein kinase (PKA) [6]. Spatial organization brings specificity to CAMP signaling via A-kinase-anchoring proteins (AKAPs) that place PKA close to their substrates, also ensuring appropriate temporal control $[7,8]$. Besides the A-kinase binding domain (AKB), all AKAPs have specific targeting domains, which enable PKA-AKAP complexes to be positioned in a membrane, organelle or other subcellular organization. In addition, these complexes may contain binding domains for other cAMP effectors and signaling molecules $[9,10]$.

Ezrin belongs to the ERM (ezrin-radixin-moesin) family of proteins [11]. In addition to the role of ERM proteins in organizing the cortical cytoskeleton by connecting actin filaments to the plasma membrane, ERM proteins also serve as scaffolds to directly organize signaling components, for example in T cell receptor signaling where Ezrin serves as an AKAP for PKA, in the insulin secretory pathway and during apoptosis [12-16]. In a soluble state the N-terminal, transmembrane receptor binding domain of ERM proteins interacts with the C-terminal, actin-binding domain, leaving ERM proteins in a folded and inactive state [17]. The association with PKA is hindered when Ezrin is in the folded configuration, but the Ezrin AKB, located in the middle alpha-helical region, becomes accessible for PKA binding when Ezrin is activated by phosphorylation of the C-terminal threonine (T567) and unfolds $[14,18]$.

We recently showed that in placental cytotrophoblasts, Ezrin functions as an AKAP to confer human chorion gonadotropin (hCG)-driven cAMP regulation of cell fusion [19]. In the placenta, GJ opening is accomplished by $\mathrm{Cx} 43$ phosphorylation by an anchored pool of PKA, bound to Ezrin in complex with Cx43 [19]. In order to assess whether Ezrin regulates GJ opening also in other nonfusogenic cell types, we examined an epithelial liver cell line with $\mathrm{C} \times 43$ as the predominant GJ protein and found that Ezrin coordinates a supramolecular complex with PKA and Cx43 that facilitates regulation of GJ communication by cAMP. 


\section{Material and methods}

\subsection{Cells}

The rat liver epithelial cell line IAR20 was cultured at $37^{\circ} \mathrm{C} 5 \% \mathrm{CO}_{2}$ in DMEM high glucose GlutaMAX medium (Gibco) supplemented with 10\% fetal bovine serum (Gibco) and 1\% PenStrep (Gibco). All the experiments were done with $90-100 \%$ confluent cells (grown in different dishes depending on the experiment). The cells were routinely examined for infections, tested for mycoplasma and were free of contamination.

\subsection{Reagents}

8-CPT-cAMP (Biolog), [ ${ }^{32}$ P $]$ p-ATP (Pierce), ATP (Sigma), cAMP (Sigma).

\subsection{Peptides}

All peptides used were synthesized on an Intavis MultiPep robot (Intavis Bioanalytical Instruments AG), uncoupled and verified by high performance liquid chromatography (HPLC). The concentrations of the peptides were determined by amino acid analysis (Thermo Scientific Dionex). Ht31 R11DLIEEAASRIVDAVIEQVKAAGAY; $\quad$ ppHt31 R11-DLIEEAASRPVDAVPEQVKAAGAY; PKI-Arg: R9TYADFIASGRTGRRNAI; PKI-Arg-Scr: R9-RRANITSGYFDTIAAGR; CX43 wt R9-DQRPSSRASSRASSRPRP; CX43 mut R9-DQRPSSRASSEASSRPRP.

\subsection{Confocal immunofluorescence microscopy}

The immunostaining was performed on cells that were fixed and permeabilized in $100 \%$ methanol for 3-5 min at $-20^{\circ} \mathrm{C}$, after which they were incubated with primary antibodies against $\mathrm{C} \times 43$ (Rabbit polyclonal, 1:400, Sigma, C6219; Mouse, 1:100, Invitrogen, 13-8300), Ezrin (Rabbit polyclonal, 1:1000, Sigma, E1281; Mouse, 1:100, Invitrogen, 35-7300) ZO-1 (Mouse monoclonal, 1:100, Invitrogen, 339100), PKA Rla (mouse monoclonal, 1:100, BD Transduction Laboratories, 610610) and PKA RIla (mouse monoclonal, 1:100, BD Transduction Laboratories, 612243) for $30 \mathrm{~min}$ at room temperature. As secondary antibodies, anti-mouse or anti-rabbit fluorochrom-conjugated antibodies were used (Alexa Fluor 488 (Jackson) and 546 (Invitrogen), 1:500) for $30 \mathrm{~min}$ at room temperature. Nuclei were counter-stained with DAPI. Images of confocal slices were acquired with Zeiss LSM 510Meta confocal microscope, using a $63 x$ oil immersion objective (NA 1.4) at $20^{\circ} \mathrm{C}$ with ZEN Software and further processed in Adobe Photoshop. Images were only adjusted for brightness and contrast in the same manner. 


\subsection{Western blotting}

Whole cell extracts were prepared in RIPA buffer, cells were sonicated and centrifuged $10,000 \mathrm{~g}$ for $10 \mathrm{~min}$ at $4{ }^{\circ} \mathrm{C}$. Supernatants were collected and protein extract prepared in SDS Loading buffer for Western blot analyses. Ten $\mu \mathrm{g}$ of protein was loaded on gels and antibodies to the following proteins were applied: Cx43 (rabbit polyclonal, 1:8000, Sigma, C6219), Cx43 (mouse monoclonal, 1:500, Sigma, C8093), Ezrin (rabbit polyclonal, 1:2000, Sigma, E1281), phospho-Ezrin (Thr567) (monoclonal rabbit, 1:1000, Cell Signaling, 3149), PKA RI $\alpha$ (mouse monoclonal, BD Transduction Laboratories, 1:1000), PKA RIla (mouse monoclonal, BD Transduction Laboratories, 1:1000), PKA C (rabbit polyclonal, 1:1000, Santa Cruz, sc-905), PKA C (mouse monoclonal, 1:1000, BD Transduction Laboratories), ZO-1 (mouse monoclonal, 1:250, Invitrogen, 33-9100), phospho-PKA substrate (rabbit monoclonal, 1:1000, Cell Signaling, 9624) and vinculin (mouse monoclonal, 1:3000, Sigma, V9131). After using secondaryHRP-conjugated antibodies, blots were developed with Supersignal West Pico or Dura substrates (Thermo Scientific).

\subsection{Immunoprecipitation}

Dynabeads ${ }^{\circledR}$ Protein $\mathrm{G}$ Immunoprecipitation kits were applied using protein extracts prepared as described above at a concentration of $1-2 \mathrm{mg} / \mathrm{mg}$ and $10 \mu \mathrm{g}$ of primary antibody used, according to the manufacturer. Nonspecific rabbit and mouse IgG antibodies (Jackson ImmunoResearch) were used as controls. IPs, IgG controls and lysates are from the same gels. Some lysates are from different exposures. Images of blots were only adjusted for brightness and contrast in the same manner.

\subsection{Mass spectrometry}

Protein identification in immunoprecipitates was done by NanoLC-ESI-MS after tryptic digestion as described [20]. The complete rat proteome databased was used and proteins of interest indicated.

\subsection{Duolink Proximity Ligation Assay (PLA)}

Applying the same fixation and permeabilization protocol as for the immunofluorescence, PLA assays were performed according to the manufacturer's instructions (Sigma). For the visualization, Duolink in situ detection reagent orange was used (Sigma). Cell membrane staining was done with Wheat Germ Agglutinin (WGA) (5ug/ml) conjugated with Alexa 488 (Life technologies) and nuclei were 
visualized with DAPI. Images of confocal slices were acquired with Zeiss LSM 510Meta confocal microscope and adjusted for brightness and contrast in the same manner. PLA signal was assessed after the treatment with peptides $\mathrm{Ht} 31$ and ppHt31 $(25 \mu \mathrm{M})$ together with 8-CPT-cAMP $(100 \mu \mathrm{M})$. Control experiments were performed with just one primary antibody in the incubation or with a pair of IgG (rabbit and mouse) control antibodies. The signal was quantified using ImageJ.

\subsection{PKA Kinase Assay}

The assay was based on the previously published method [21] with some modifications. Immunoprecipitations were performed as previously described and precipitates incubated in a kinase

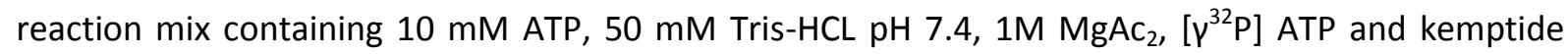
(Leu-Arg-Arg-Ala-Ser-Leu-Gly) with cAMP $(5 \mu \mathrm{M}) \pm$ PKI $(10 \mu \mathrm{M})$ for $9 \mathrm{~min}$ at $30^{\circ} \mathrm{C}$. The reaction mixture was spotted on phosphocellulose paper, washed 4 times in $75 \mathrm{mM}$ phosphoric acid, once in $95 \%$ ethanol, dried and counted by liquid scintillation.

\subsection{0. siRNA transfection}

Lipofectamine RNAiMAX transfection reagent (Invitrogen) was used for siRNA knock down experiments according to the manufacturer's instructions. Cx43 siRNA: 5'ACUAGCUGCUGGACAUGATT 3', 5' UUCAUGUCCAGCAGCUAGUTT 3'. Stealth RNAi negative control medium GC duplex (Invitrogen) was used as a siRNA control.

2.11. Calcein dye transfer-based assay for gap junction intercellular communication (GJIC)

A cell-based assay for higher throughput GIIC assessment using IAR20 cells was developed as described in [51]. In brief, the assay implied loading one population of IAR20 cells with calcein, mixing it 1:1 with an unlabeled cell population, plating the cells at a density where they formed gap junctions and 4 hours later measuring dye transfer by assessing the increased number or dye positive cells using the IncuCyte Zoom instrument.

\subsection{Gap-Fluorescence Recovery After Photobleaching (gap-FRAP)}

For assessment of GIIC in live cells, a quantitative gap-FRAP assay based on calcein red-orange AM dye (2.5 $\mu \mathrm{M}$, Invitrogen) was performed [22]. An Olympus FluoView 1000 inverted microscope equipped with a 60x PlanApo (NA 1.3) oil immersion objective was used at $37^{\circ} \mathrm{C}$ with DMEM (high 
glucose, HEPES, no phenol red, 21063-029, Gibco) imaging medium. Olympus acquisition software was applied. The exponential fluorescence recovery curves were formed using the equation: $\left(F_{i}-F_{t}\right) /$ $\left(F_{i}-F_{0}\right)=c^{-t / \tau}$, where $F_{i}, F_{t}$ and $F_{0}$ are fluorescence intensities before bleaching, at a certain time point $t$ and time 0 , respectively, and $\tau$ is a time constant. The transfer rate constant $k=1 / \tau$ was calculated and corrected for the number of neighboring cells surrounding the bleached cell.

\subsection{Statistics}

GraphPad Prism software was used for all the statistical analysis and unpaired t-test or ManWhitney test applied for comparison between groups, depending on the data. All the data are shown as mean \pm SD. ${ }^{*} p<0.05, * * p<0.01, * * * p<0.005$.

\section{Results}

3.1. The GJ protein Cx43 forms a supramolecular complex with Ezrin and PKA at the cell membrane of IAR20 cells

In order to examine the presence and localization of the AKAP Ezrin and PKA in epithelial cells, the liver cell line IAR20, which forms abundant GJs, was subjected to confocal immunofluorescence analysis. Immunostaining showed that Ezrin is present in IAR20 cell membranes and that it codistributed with $C_{x} 43$, which is known to be the predominant $C_{x}$ isoform expressed in this cell line [23, 24] (Fig. 1). The main region of co-distribution between Cx43 and Ezrin appeared to be in GJ plaques [24] (Fig. 1). Ezrin is a dual-specific AKAP [25], and both PKA type I and type II, represented by the regulatory subunits RI $\alpha$ and RIl $\alpha$, were found to be abundantly expressed in IAR20 cells and co-distributed with $\mathrm{Cx} 43$ and Ezrin in the IAR20 cell membrane (Fig. 1). It has previously been shown that zonula occludens 1 (ZO-1) may form a complex with Cx43 [26] and we also observed codistribution of Cx43 and ZO-1 in IAR20 cells, particularly in the cell membrane (Fig. 1).

Western blot analysis of IAR20 cell lysates was performed to examine the levels of total and phosphorylated Ezrin. Phosphorylation of Ezrin at T567 is involved in its activation process $[14,18]$. Ezrin was detected in IAR20 cell lysates both by antibodies against total Ezrin as well as Ezrin phosphorylated at T567 (Fig. 2A). Immunoblotting also demonstrated the expression of both PKA regulatory subunits, Rl $\alpha$ and RIl $\alpha$, catalytic subunit (PKA C), ZO-1, as well as Cx43. In accordance with previous studies in various cell types, $C_{x} 43$ formed three distinct bands on SDS-PAGE, termed $P_{0}, P_{1}$ and $\mathrm{P}_{2}$, which represent differently phosphorylated forms of $\mathrm{Cx} 43$ (Fig. 2A) $[27,28]$. 
To examine whether the Cx43-ZO-1 complex physically interacts with Ezrin and PKA, coimmunoprecipitations of the proteins were performed. As shown in Fig. 2B, Ezrin immunoprecipitation pulled down Cx43, PKA RI $\alpha$, Rll $\alpha$ and PKA C (Fig. 2B). Similarly, when Cx43, ZO-1, PKA Rl $\alpha$ and RIl $\alpha$ and PKA C were immunoprecipitated, the same co-immunoprecipitated components were found (Fig. 2B). Rabbit and mouse IgGs were used as controls and did not precipitate any of the proteins examined (Fig. 2B). Proteomic analysis performed on the $\mathrm{C} \times 43$ immunoprecipitate identified Ezrin and the PKA RIl $\alpha$ subunit (Fig. 2C). In addition, the PKA C subunit beta was present in the immunoprecipitates (Fig. 2C). Collectively, these data suggest the presence of a supramolecular complex in IAR20 cells where Ezrin bound to the Cx43-ZO-1 complex anchors PKA (Fig. 2D).

To further examine the co-localization of the proteins in this complex, proximity ligation assay (PLA) was performed, in which IAR20 cells were labelled with pairs of antibodies against the various complex members. Close proximity between proteins $(<40 \mathrm{~nm})$ is indicated by a strong red-dotted signal, which was observed when Cx43-ZO-1, Ezrin-PKA Rl $\alpha$ and Ezrin-RIl $\alpha$ colocalization was examined (Fig. 3A). The signal was particularly intense in the cell membrane regions (Fig. 3A). The coincubation of $\mathrm{Cx} 43$ and Ezrin antibodies was found to yield the most intense PLA signal, which may suggest that these proteins have the shortest distance among the proteins analyzed (Fig. 3A). In contrast, when IAR20 cells were labelled with a single antibody or a pair of unspecific IgG (rabbit and mouse) controls, no signal was detected (Supplementary Fig. S1). Preincubating the cells with the cell permeable version of the $\mathrm{Ht} 31$ peptide, which is a PKA anchoring disruptor with dual specificity for RI and RII regulatory subunits [29], prevented the PLA signal generation for all antibody pairs involving PKA ( $p<0.005)$, indicating that it displaced PKA Rla and Rll $\alpha$ from Ezrin (Fig. 3B). In contrast, preincubating the cells with the control peptide ppHt31 did not have any effect on the PLA signal (Fig. 3B).

\subsection{The Ezrin-PKA complex phosphorylates $\mathrm{Cx} 43$}

As the above data indicated that $\mathrm{Cx} 43$ and ZO- 1 form a complex together with Ezrin and PKA in IAR20 cells, we next found it of importance to examine whether PKA can directly phosphorylate Cx43 and thereby affect GJ gating. The direct role of PKA in Cx43 phosphorylation has been unclear, and it has been suggested that $\mathrm{C} \times 43$ is a poor substrate for PKA, unlike its role as a substrate for PKC and MAPK [30-32]. To assess the level of Cx43-associated PKA activity, a kemptide-based kinase assay was performed. As evident from Fig. 4A, PKA C, Ezrin and Cx43 immunoprecipitates had cAMP-stimulated and protein kinase inhibitor $(\mathrm{PKI})$-inhibitable $(p<0.05)$ phosphotransferase activity that significantly 
differed $(p<0.05)$ from that associated with IgG precipitates, used as controls (Fig. $4 A$ ). Furthermore, stimulation of cells with 8-CPT-cAMP produced a mobility shift in Cx43. When analyzed by SDS-PAGE, Cx43 shows multiple electrophoretic isoforms (as shown in Fig. $2 A$ ), named $P_{0}$, which is a faster migrating form with few phosphorylated sites [33], and $P_{1}$ and $P_{2},[27,34,35]$, both of which migrate slower due to phosphorylation at specific sites that induce conformational changes and shift in mobility. Since several kinases phosphorylate $\mathrm{Cx} 43$, treatment of cells with chemicals like 12-0tetradecanoylphorbol-13-acetate (TPA) or growth factors such as epidermal growth factor (EGF), which activates a variety of kinases, leads to Cx43 mobility shifts [36]. Control and 8-CPT-cAMPpretreated cells were lysed and analyzed by western blot using an anti-phospho-PKA phosphorylation site antibody that detects specific motifs (RRXS, RXXS and RXS) in proteins phosphorylated by PKA and which detects phosphorylation in $\mathrm{C} \times 43$ (data not shown). The data demonstrated a shift in $\mathrm{C} \times 43$ mobility towards the $P_{2}$ isoform following cAMP treatment ( $p<0.05$ ) (Fig. 4B). siRNA-mediated $C x 43$ knock down was performed to verify that the bands indeed represented $\mathrm{C} x 43$ and not unspecific bands (Fig. 4B). Efficiency of the knock-down was close to $100 \%$. Samples treated with control siRNA showed a similar pattern of the $\mathrm{Cx} 43$ phospho-forms as non-treated cells. To further analyze the effect of 8-CPT-CAMP on the Cx43 phosphorylation status, antibodies against unphosphorylated and phosphorylated $\mathrm{Cx} 43$ isoforms were used separately. Stimulation with 8-CPT-CAMP was found to significantly change $(p<0.05)$ the ratio between unphosphorylated/phosphorylated $\mathrm{Cx} 43$ towards the phosphorylated form (Fig. 4C). Using a live cell assay for calcein dye transfer to assess GJIC in IAR20 cells, we next examined the effect of a cell-permeable version of PKI alone and together with cAMP. As evident from Fig. 4D, cAMP increased GJIC (bottom panel). PKI, but not its scrambled control reduced both basal and CAMP-stimulated GIIC (top and bottom panels, respectively). Together our data indicate that CAMP through activation of an anchored pool of PKA, directly or indirectly, elicits phosphorylation of $\mathrm{C} \times 43$.

\subsection{Ezrin-anchored PKA controls $\mathrm{Cx} 43$ gap junction intercellular communication}

Our data demonstrate the importance of PKA kinase activity when PKA is in complex with $\mathrm{Cx} 43$ and the changes in $\mathrm{Cx} 43$ phosphorylation when PKA is being activated. In order to examine whether Ezrin-mediated Cx43 phosphorylation functionally affects GJIC in live cells, quantitative gap-FRAP experiments were performed. Whole cells in a confluent monolayer were subjected to photobleaching and the fluorescence recovery that occurs as a consequence of the calcein dye passage through the GJs from the neighboring (non-photobleached cells) was measured (Fig. 5A). The fluorescence recovery was monitored during 600s post bleaching, which was estimated to be 
sufficient time for reaching the plateau in cAMP-treated cells (Fig. 5B). The florescence recovery was significantly faster upon cAMP stimulation and slower when cells were loaded with a cell-permeable version of the $\mathrm{Ht} 31$ peptide together with CAMP (Fig. 5B). Interestingly, cells subjected to $\mathrm{Ht} 31$ treatment did not recover their GJIC even after 600s (Fig. 5B). The proline-substituted ppHt31 peptide used as a control together with cAMP did not affect the recovery rate (Fig. 5B). Calcein transfer rate constant $(k)$ analysis furthermore supported the observation that CAMP increases intercellular communication $(p<0.05$ ) over the total recorded time of 600 s and particularly in the first 150 s of the recovery $(p<0.001$ ) (Fig. $5 C-D)$. Ht31 treatment significantly lowered the $k$ value during the starting 150s $(p<0.01)$, as well as for the total 600s ( $<<0.005)$ (Fig. $5 C-D)$. Furthermore, treatment with a cell-permeable peptide from the $\mathrm{Cx} 43$ sequence that interacts with Ezrin [19], which was specifically designed to disrupt the Cx43-Ezrin interaction ( $\mathrm{C} \times 43 \mathrm{wt}$ ) [51], significantly reduced the CAMP-induced increase in communication compared to a control peptide with a substitution in the amino acid crucial for binding ( $\mathrm{C} \times 43$ mut). The transfer rate constant was significantly lower for the first 150s $(p<0.01)$ as well as for the total 600s ( $p<0.05)$ (Fig. 5E). To test our hypothesis that that GJIC assessed with the gap-FRAP technique represents traffic through $\mathrm{Cx} 43$ hexamers, Cx43 was knocked down by transfection with siRNA, which caused loss of GJIC, while control siRNA transfection did not have any significant effect on the communication (Fig. 5F). The transfection efficiency was $97 \%$.

\section{Discussion}

The discovery that Ezrin is a dual-specific AKAP in placental trophoblasts responsible for regulation of GIIC, raised the question of whether Ezrin also in other cell systems serves as an AKAP that confers PKA phosphorylation of Cx43 and channel opening. In the placenta, cytotrophoblasts fuse and form multinucleated syncytium, which is a hormone driven process that is known to involve cAMP signaling pathway [37]. Fusogenic signal transmission through Cx43 GJs is needed for the fusion process to proceed [38]. However, it has remained elusive whether regulation of GJIC by an Ezrinanchored pool of PKA applies to other non-fusogenic cell types. In this study, we demonstrate that in epithelial IAR20 cells, Ezrin is a membrane-anchored AKAP that associates with the Cx43-ZO-1 complex and places PKA in proximity to $\mathrm{Cx} 43$. Our data indicate that Ezrin facilitates $\mathrm{Cx} 43$ phosphorylation and regulation of GJ channel permeability also in non-fusogenic cells. Similar observations were also made in HEK cells (not shown).

Cx43 phosphorylation affects GJ channels at different levels, including GJ assembly and disassembly, degradation, and interaction with other proteins as well as channel permeability [39]. A number of serines in the $\mathrm{C}$ terminal region of $\mathrm{Cx} 43$ are potential targets for different kinases as recently 
reviewed [39]. Several studies have reported that PKA is involved in GJ assembly [31, 40-42]. PKC has been shown to abolish GJ assembly as well as communication [43]. Phosphorylation of Cx43 by casein kinase 1 might potentiate cell communication by increasing GJ assembly, whereas Src and MAPK activity have been shown to lead to the closing of the GJ channels [44, 45]. Positive regulation of GIIC by hCG stimulation of cytotrophoblast was in accordance with previous studies, where cAMP stimulation promoted cell communication in numerous cell types or application of PKA catalytic subunit resumed PKI reduced cell communication in primary ovarian granulosa cells $[42,46]$. Finally, we showed that the AKAP Ezrin spatiotemporally regulates the process of GJ opening and facilitated communication [19].

IAR20 cells are known to express Cx43 [23] and show quite high levels of GJIC [47, 48]. Immunolocalization experiments and western blot analysis indicated that IAR20 cells also express Ezrin and both PKA regulatory subunits (RI $\alpha$ and RIl $\alpha$ ). Co-immunoprecipitation, mass spectrometry and PLA showed that there is a physical interaction between Cx43-ZO-1 and Ezrin-PKA, which together form a supramolecular complex that localizes in the membrane. PKA C is also found in the complex which is not surprising since Smith et al. showed that PKA C remains in the complex with RIl $\alpha$ and AKAP18y upon PKA activation by cAMP [49], which presumably would be the situation in complexes with other AKAPs too. ZO-1 probably interacts with the $\mathrm{C}$ terminal part of $\mathrm{Cx} 43$, as shown elsewhere $[19,50]$. The strong PLA signal between a pair of antibodies to Ezrin and Cx43 suggests close proximity and possibly direct binding of the two proteins. Although Ezrin is a dual-specific AKAP, the RIl $\alpha$ subunit of PKA appeared to interact more with Ezrin than Rl $\alpha$, according to the immunofluorescence experiments as well as the PLA. A similar observation was made in placental syncytia, where levels of Rl $\alpha$ co-localization with Ezrin also were lower than those of Rlla and Ezrin [19]. It is known that Rla has faster off-rate from Ezrin than RII, which could mean that the RIla-Ezrin complex is favoured [14].

By a biochemical approach we demonstrated that activation of PKA is able to directly or indirectly trigger phosphorylation of $\mathrm{Cx} 43$ inside cells. This process is Ezrin-dependent, supporting previous observations of ERM protein involvement in signaling events [13-16]. Silencing and reconstitution experiments in trophoblasts indicated a central role for Ezrin and GJIC in the fusion process [19]. It was, however, unclear if PKA actually phosphorylates Cx43 directly or if this effect is indirect and acting via some other kinase. Some studies speculated that $\mathrm{Cx} 43$ is a relatively poor substrate for PKA, especially compared to PKC and MAPK [30-32]. However, Pidoux et al. demonstrated that loss of PKA from the Ezrin-Cx43-ZO-1 complex prevented cell fusion and syncytial formation due to the channel closure, indicating that a direct role for PKA is necessary for controlling GJIC in these cells [19]. 
How manipulation of the Cx43-Ezrin-PKA complex affects GJIC was analyzed by calcein dye transfer in the gap-FRAP assay. Displacing PKA from its AKAP Ezrin using Ht31 disabled Cx43 phosphorylation by PKA and thereby channel opening, which slowed the recovery of calcein. In addition, the recovery was not complete after $\mathrm{Ht} 31$ treatment compared to untreated cells, suggesting that many channels remain closed for a period of time. Treatment with the specific Cx43-Ezrin interaction disruptor peptide reduced the communication between IAR20 cells in the gap-FRAP experiments, compared to a control peptide with a substitution in the amino acid crucial for binding [19]. The same effect was observed in experiments from a cell-based assay for assessing gap junction communication that we have recently developed [51]. These live cell imaging data indicate that Ezrin is the AKAP anchoring PKA in IAR20 cells. Furthermore, Ht31 peptide had the same effect in the PLA assay, abolishing the signal. A similar finding was observed in trophoblasts treated with RIAD and super-AKAP-IS, which displace RI and RII, respectively, from Ezrin [19]. Moreover, knockdown of Ezrin or Cx43 in trophoblast and reconstitution experiments with $\mathrm{Cx} 43$ or Ezrin mutated in the binding domain also cause loss of communication [19].

Our data support a model of GJIC regulation in IAR20 cells where increase in the local CAMP pool activates an anchored PKA leading to $\mathrm{Cx} 43$ phosphorylation, promoting GJ opening. This illustrates that regulation of GJIC by an Ezrin-anchored PKA is a general principle and not just a phenomenon in fusogenic cells. Since there are multiple phosphorylation sites in $\mathrm{C} \times 43$ that are available for PKA activity, it is to be investigated which ones are PKA specific. Although S364 is the phospho-site typically associated with the PKA-mediated effect on GJIC [30,31], mostly due to the increase in the GJ assembly, others sites on the same region also fit the PKA consensus sequence and could be involved.

The fact that anchored PKA may act as a gatekeeper to control GJIC in different cell types opens possibilities for targeting the Cx43-Ezrin interaction in conditions of impaired GJ communication, where it is known that Cx43 plays an important role. In cancer, GJ communication affects cell proliferation, migration and plasticity [52]. It has been recently shown that orally bioavailable modulators of $\mathrm{Cx} 43$ gap junctions suppressed brain metastasis in mice [53]. Inhibition of anti-tumor immunity by regulatory T cells could potentially be reversed by targeting GJ [54]. Furthermore, in the heart, Cx43 GJ regulation could limit heart damage after myocardial infarction [55]. However, it remains to be shown that an Ezrin-anchored pool of PKA is present and regulates GJIC in these systems. 


\section{Conflict of interest}

The authors declare no conflict of interest.

\section{Acknowledgements}

This work was supported by the Norwegian Cancer Society [grant number 419544], the Research Council of Norway [grant number 187615], the K.G. Jebsen Foundation [grant number 2012/21 and 2012/23] and the Novo Nordic Foundation [grant number NFF14OC001090]. The authors acknowledge the use of the RCN supported NorMIC Oslo Imaging platform.

\section{References}

[1] D.A. Goodenough, J.A. Goliger, D.L. Paul, Connexins, connexons, and intercellular communication, Annu Rev Biochem 65 (1996) 475-502.

[2] K. Willecke, J. Eiberger, J. Degen, D. Eckardt, A. Romualdi, M. Guldenagel, U. Deutsch, G. Sohl, Structural and functional diversity of connexin genes in the mouse and human genome, Biol Chem 383(5) (2002) 725-37.

[3] A. De Maio, V.L. Vega, J.E. Contreras, Gap junctions, homeostasis, and injury, J Cell Physiol 191(3) (2002) 269-82.

[4] C.C. Naus, D.W. Laird, Implications and challenges of connexin connections to cancer, Nat Rev Cancer 10(6) (2010) 435-41.

[5] C.J. Wei, X. Xu, C.W. Lo, Connexins and cell signaling in development and disease, Annu Rev Cell Dev Biol 20 (2004) 811-38.

[6] P.D. Lampe, A.F. Lau, The effects of connexin phosphorylation on gap junctional communication, Int J Biochem Cell Biol 36(7) (2004) 1171-86.

[7] G. Pidoux, K. Tasken, Specificity and spatial dynamics of protein kinase A signaling organized by Akinase-anchoring proteins, J Mol Endocrinol 44(5) (2010) 271-84.

[8] K. Tasken, E.M. Aandahl, Localized effects of CAMP mediated by distinct routes of protein kinase A, Physiol Rev 84(1) (2004) 137-67.

[9] Z.E.H. Daniel W. Carr, lain D. C. Fraser\$, Renata E. Stofko-Hahn, and JohDn, Scott, Association of the Type I1 CAMP-dependent Protein Kinase with a

Human Thyroid RII-anchoring Protein, (1992).

[10] M.G. Gold, B. Lygren, P. Dokurno, N. Hoshi, G. McConnachie, K. Tasken, C.R. Carlson, J.D. Scott, D. Barford, Molecular basis of AKAP specificity for PKA regulatory subunits, Mol Cell 24(3) (2006) 383-95. [11] V.M. Berthoud, M.B. Rook, O. Traub, E.L. Hertzberg, J.C. Saez, On the mechanisms of cell uncoupling induced by a tumor promoter phorbol ester in clone 9 cells, a rat liver epithelial cell line, Eur J Cell Biol 62(2) (1993) 384-96.

[12] A.L. Neisch, R.G. Fehon, Ezrin, Radixin and Moesin: key regulators of membrane-cortex interactions and signaling, Curr Opin Cell Biol 23(4) (2011) 377-82.

[13] J.K. Burkhardt, E. Carrizosa, M.H. Shaffer, The actin cytoskeleton in T cell activation, Annu Rev Immunol 26 (2008) 233-59.

[14] A. Ruppelt, R. Mosenden, M. Gronholm, E.M. Aandahl, D. Tobin, C.R. Carlson, H. Abrahamsen, F.W. Herberg, O. Carpen, K. Tasken, Inhibition of T cell activation by cyclic adenosine 5'- 
monophosphate requires lipid raft targeting of protein kinase $A$ type I by the A-kinase anchoring protein ezrin, J Immunol 179(8) (2007) 5159-68.

[15] M.H. Shaffer, R.S. Dupree, P. Zhu, I. Saotome, R.F. Schmidt, A.I. McClatchey, B.D. Freedman, J.K. Burkhardt, Ezrin and moesin function together to promote T cell activation, J Immunol 182(2) (2009) 1021-32.

[16] A.J. Stokka, R. Mosenden, A. Ruppelt, B. Lygren, K. Tasken, The adaptor protein EBP50 is important for localization of the protein kinase A-Ezrin complex in T-cells and the immunomodulating effect of cAMP, Biochem J 425(2) (2010) 381-8.

[17] R. Gary, A. Bretscher, Heterotypic and homotypic associations between ezrin and moesin, two putative membrane-cytoskeletal linking proteins, Proc Natl Acad Sci U S A 90(22) (1993) 10846-50.

[18] B.T. Fievet, A. Gautreau, C. Roy, L. Del Maestro, P. Mangeat, D. Louvard, M. Arpin, Phosphoinositide binding and phosphorylation act sequentially in the activation mechanism of ezrin, J Cell Biol 164(5) (2004) 653-9.

[19] G. Pidoux, P. Gerbaud, J. Dompierre, B. Lygren, T. Solstad, D. Evain-Brion, K. Tasken, A PKA-ezrin$\mathrm{Cx} 43$ signaling complex controls gap junction communication and thereby trophoblast cell fusion, $\mathrm{J}$ Cell Sci 127(Pt 19) (2014) 4172-85.

[20] T. Solstad, E. Bjorgo, C.J. Koehler, M. Strozynski, K.M. Torgersen, K. Tasken, B. Thiede, Quantitative proteome analysis of detergent-resistant membranes identifies the differential regulation of protein kinase $C$ isoforms in apoptotic T cells, Proteomics 10(15) (2010) 2758-68. [21] J.D. Corbin, E.M. Reimann, Assay of cyclic AMP-dependent protein kinases, Methods Enzymol 38 (1974) 287-90.

[22] M.H. Wade, J.E. Trosko, M. Schindler, A fluorescence photobleaching assay of gap junctionmediated communication between human cells, Science 232(4749) (1986) 525-8.

[23] M. Asamoto, M. Oyamada, A. el Aoumari, D. Gros, H. Yamasaki, Molecular mechanisms of TPAmediated inhibition of gap-junctional intercellular communication: evidence for action on the assembly or function but not the expression of connexin 43 in rat liver epithelial cells, Mol Carcinog 4(4) (1991) 322-7.

[24] T.A. Fykerud, A. Kjenseth, K.O. Schink, S. Sirnes, J. Bruun, Y. Omori, A. Brech, E. Rivedal, E. Leithe, Smad ubiquitination regulatory factor-2 controls gap junction intercellular communication by modulating endocytosis and degradation of connexin43, J Cell Sci 125(Pt 17) (2012) 3966-76.

[25] E. Jarnaess, A. Ruppelt, A.J. Stokka, B. Lygren, J.D. Scott, K. Tasken, Dual specificity A-kinase anchoring proteins (AKAPs) contain an additional binding region that enhances targeting of protein kinase A type I, J Biol Chem 283(48) (2008) 33708-18.

[26] B.N. Giepmans, W.H. Moolenaar, The gap junction protein connexin43 interacts with the second PDZ domain of the zona occludens-1 protein, Curr Biol 8(16) (1998) 931-4.

[27] L.S. Musil, B.A. Cunningham, G.M. Edelman, D.A. Goodenough, Differential phosphorylation of the gap junction protein connexin43 in junctional communication-competent and -deficient cell lines, J Cell Biol 111(5 Pt 1) (1990) 2077-88.

[28] L.S. Musil, E.C. Beyer, D.A. Goodenough, Expression of the gap junction protein connexin43 in embryonic chick lens: molecular cloning, ultrastructural localization, and post-translational phosphorylation, J Membr Biol 116(2) (1990) 163-75.

[29] A.J. Stokka, F. Gesellchen, C.R. Carlson, J.D. Scott, F.W. Herberg, K. Tasken, Characterization of Akinase-anchoring disruptors using a solution-based assay, Biochem J 400(3) (2006) 493-9.

[30] M.M. Shah, A.M. Martinez, W.H. Fletcher, The connexin43 gap junction protein is phosphorylated by protein kinase $A$ and protein kinase $C$ : in vivo and in vitro studies, Mol Cell Biochem 238(1-2) (2002) 57-68.

[31] E.M. TenBroek, P.D. Lampe, J.L. Solan, J.K. Reynhout, R.G. Johnson, Ser364 of connexin43 and the upregulation of gap junction assembly by cAMP, J Cell Biol 155(7) (2001) 1307-18.

[32] B.J. Warn-Cramer, P.D. Lampe, W.E. Kurata, M.Y. Kanemitsu, L.W. Loo, W. Eckhart, A.F. Lau, Characterization of the mitogen-activated protein kinase phosphorylation sites on the connexin-43 gap junction protein, J Biol Chem 271(7) (1996) 3779-86. 
[33] J.L. Solan, M.D. Fry, E.M. TenBroek, P.D. Lampe, Connexin43 phosphorylation at S368 is acute during $S$ and G2/M and in response to protein kinase C activation, J Cell Sci 116(Pt 11) (2003) 2203-11. [34] J.L. Solan, P.D. Lampe, Connexin43 phosphorylation: structural changes and biological effects, Biochem J 419(2) (2009) 261-72.

[35] J.L. Solan, L. Marquez-Rosado, P.L. Sorgen, P.J. Thornton, P.R. Gafken, P.D. Lampe, Phosphorylation at S365 is a gatekeeper event that changes the structure of $\mathrm{C} \times 43$ and prevents down-regulation by PKC, J Cell Biol 179(6) (2007) 1301-9.

[36] S. Sirnes, A. Kjenseth, E. Leithe, E. Rivedal, Interplay between PKC and the MAP kinase pathway in Connexin43 phosphorylation and inhibition of gap junction intercellular communication, Biochem Biophys Res Commun 382(1) (2009) 41-5.

[37] P. Gerbaud, G. Pidoux, Review: An overview of molecular events occurring in human trophoblast fusion, Placenta 36 Suppl 1 (2015) S35-42.

[38] J.L. Frendo, L. Cronier, G. Bertin, J. Guibourdenche, M. Vidaud, D. Evain-Brion, A. Malassine, Involvement of connexin 43 in human trophoblast cell fusion and differentiation, J Cell Sci 116(Pt 16) (2003) 3413-21.

[39] J.L. Solan, P.D. Lampe, Specific Cx43 phosphorylation events regulate gap junction turnover in vivo, FEBS Lett 588(8) (2014) 1423-9.

[40] M.M. Atkinson, P.D. Lampe, H.H. Lin, R. Kollander, X.R. Li, D.T. Kiang, Cyclic AMP modifies the cellular distribution of connexin43 and induces a persistent increase in the junctional permeability of mouse mammary tumor cells, J Cell Sci 108 ( Pt 9) (1995) 3079-90.

[41] P.D. Lampe, Analyzing phorbol ester effects on gap junctional communication: a dramatic inhibition of assembly, J Cell Biol 127(6 Pt 2) (1994) 1895-905.

[42] R.C. Burghardt, R. Barhoumi, T.C. Sewall, J.A. Bowen, Cyclic AMP induces rapid increases in gap junction permeability and changes in the cellular distribution of connexin43, J Membr Biol 148(3) (1995) 243-53.

[43] J.F. Ek-Vitorin, T.J. King, N.S. Heyman, P.D. Lampe, J.M. Burt, Selectivity of connexin 43 channels is regulated through protein kinase C-dependent phosphorylation, Circ Res 98(12) (2006) 1498-505.

[44] G.T. Cottrell, R. Lin, B.J. Warn-Cramer, A.F. Lau, J.M. Burt, Mechanism of v-Src- and mitogenactivated protein kinase-induced reduction of gap junction communication, Am J Physiol Cell Physiol 284(2) (2003) C511-20.

[45] C.D. Cooper, P.D. Lampe, Casein kinase 1 regulates connexin-43 gap junction assembly, J Biol Chem 277(47) (2002) 44962-8.

[46] A.J. Godwin, L.M. Green, M.P. Walsh, J.R. McDonald, D.A. Walsh, W.H. Fletcher, In situ regulation of cell-cell communication by the cAMP-dependent protein kinase and protein kinase $C$, Mol Cell Biochem 127-128 (1993) 293-307.

[47] M.H. Juul, E. Rivedal, T. Stokke, T. Sanner, Quantitative determination of gap junction intercellular communication using flow cytometric measurement of fluorescent dye transfer, Cell Adhes Commun 7(6) (2000) 501-12.

[48] H. Opsahl, E. Rivedal, Quantitative determination of gap junction intercellular communication by scrape loading and image analysis, Cell Adhes Commun 7(5) (2000) 367-75.

[49] F.D. Smith, S.L. Reichow, J.L. Esseltine, D. Shi, L.K. Langeberg, J.D. Scott, T. Gonen, Intrinsic disorder within an AKAP-protein kinase A complex guides local substrate phosphorylation, Elife 2 (2013) e01319.

[50] B.N. Giepmans, I. Verlaan, W.H. Moolenaar, Connexin-43 interactions with ZO-1 and alpha- and beta-tubulin, Cell Commun Adhes 8(4-6) (2001) 219-23.

[51] A.R. Dukic, D.W. McClymont, K. Tasken, A Cell-Based High-Throughput Assay for Gap Junction Communication Suitable for Assessing Connexin 43-Ezrin Interaction Disruptors Using IncuCyte ZOOM, Journal of Biomolecular Screening (2016).

[52] N. Defamie, A. Chepied, M. Mesnil, Connexins, gap junctions and tissue invasion, FEBS Lett 588(8) (2014) 1331-8. 
[53] Q. Chen, A. Boire, X. Jin, M. Valiente, E.E. Er, A. Lopez-Soto, L.S. Jacob, R. Patwa, H. Shah, K. Xu, J.R. Cross, J. Massague, Carcinoma-astrocyte gap junctions promote brain metastasis by cGAMP transfer, Nature 533(7604) (2016) 493-8.

[54] T. Bopp, C. Becker, M. Klein, S. Klein-Hessling, A. Palmetshofer, E. Serfling, V. Heib, M. Becker, J. Kubach, S. Schmitt, S. Stoll, H. Schild, M.S. Staege, M. Stassen, H. Jonuleit, E. Schmitt, Cyclic adenosine monophosphate is a key component of regulatory T cell-mediated suppression, J Exp Med 204(6) (2007) 1303-10.

[55] K. Maass, S.E. Chase, X. Lin, M. Delmar, Cx43 CT domain influences infarct size and susceptibility to ventricular tachyarrhythmias in acute myocardial infarction, Cardiovasc Res 84(3) (2009) 361-7. 


\section{Figure captions}

Fig. 1. Co-distribution of Ezrin and Cx43, together with ZO-1, PKA RI $\alpha$ and RIl $\alpha$ in IAR20 cells. Cells were immunostained with combinations of antibodies to Cx43, Ezrin, ZO-1, PKA RI $\alpha$ and PKA RIl $\alpha$ in dual immunofluorescence experiments as indicated. DAPI was used for nuclear counterstaining. Enlarged image parts are showing selected regions of co-distribution in the membrane. Representative images are shown.

Fig. 2. A supramolecular complex of $C x 43$, Ezrin and PKA in IAR2O cells. (A) Immunoblots showing the presence of Cx43, ZO-1, Ezrin, PKA subunits Rl $\alpha$ and RIl $\alpha$ and catalytic subunit (C) of PKA in IAR20 cells. Whole cell lysates were subjected to western blot analysis using antibodies against Cx43, Ezrin, phospho-Ezrin (Thr567), PKA RI $\alpha$, PKA RIl $\alpha$, PKA C and ZO-1. $P_{0}, P_{1}$ and $P_{2}$ migrating forms of $C x 43$ and phospho-Ezrin band are indicated with arrows. (B) Lysates were subjected to immunoprecipitation with Ezrin, Cx43, PKA RIl $\alpha$, PKA C and ZO-1 antibodies as well as IgG controls. Immunoprecipitates and corresponding lysates were analyzed by immunoblot for the presence of the indicated proteins. Dotted lines indicate that lanes from lysates are combined from different parts of the same gel and same or different exposures. Data in A and B are representative of three experiments. (C) IAR20 cell extracts were analyzed by Nano-LC-ESI-MS after tryptic digestion of Cx43 immunoprecipitate. (D) Schematic illustration of the complex including Ezrin, PKA, Cx43 and ZO-1.

Fig. 3. Cx43, Ezrin and PKA co-localize in the IAR20 cells membrane. (A) Cells were subjected to proximity ligation assay with the following pairs of antibodies: Cx43-Ezrin, Ezrin-PKA Rl $\alpha$, Ezrin-PKA RIl $\alpha$, Ezrin-ZO-1, Cx43-PKA RI $\alpha$, Cx43-PKA RIl $\alpha$ and Cx43-ZO-1. Physical proximity of the molecules was assessed by Duolink technology generating red spots when proximity $<40 \mathrm{~nm}$. Cell membranes were stained with Wheat Germ Agglutinin (WGA) conjugated with Alexa 488 and nuclei with DAPI. Bars represent the mean \pm SEM ( $n=6)$. (B) The proximity was assessed in presence of $\mathrm{Ht} 31$ peptide or peptide ppHt31 as control, both peptides at $25 \mu \mathrm{M}$. Bars represent the mean \pm SEM from $(n=6$; $* * * \mathrm{P}<0.005)$.

Fig. 4. Phosphorylation of $\mathrm{Cx} 43$ by PKA. (A) PKA C, Ezrin and $\mathrm{C} x 43$ immunoprecipitates were subjected to kinase assays using kemptide as substrate and assessing $\gamma^{32}$ ATP incorporation. Phosphotransferase activity was examined in samples treated with cAMP $(5 \mu \mathrm{M}) \pm$ PKI $(10 \mu \mathrm{M})$. IgG 
precipitates were used as controls. Bars represent the mean \pm SD from 3 independent experiments (* $\mathrm{p}<0.05$ for cAMP vs cAMP+PKI and \# $\mathrm{p}<0.05$ for IP vs corresponding IgG IP, both for cAMP and cAMP+PKI treated samples). (B) Changes in Cx43 phosphorylation upon 8-CPT-cAMP (100 $\mu \mathrm{M})$ stimulation of the cells were detected by a phospho-PKA substrate antibody that recognizes specific motifs (RRXS*, RXXS* and RXS*) in proteins phosphorylated by PKA and compatible with the putative phosphorylation sites in $\mathrm{Cx} 43$. Arrows indicate the two different migrating forms $\mathrm{P}_{1}$ and $\mathrm{P}_{2}$. $\mathrm{Cx} 43$ - and control siRNA-transfected cells were used as controls. Dotted lines indicate that different parts of the same gel and exposure were combined. Bars represent the mean \pm SEM from 3 independent experiments (* $\mathrm{P}<0.05$ ). (C) Differential $\mathrm{C} x 43$ phosphorylation was detected by specific $\mathrm{C} \times 43$ antibodies that recognize either unphosphorylated (non-p-) or phosphorylated (-p-) form of the protein, in presence and absence of 8-CPT-CAMP (100 $\mu \mathrm{M})$ pretreatment. Vinculin immunoblots were used as loading controls. Bars represent the mean \pm SEM from 3 independent experiments $\left({ }^{*} \mathrm{P}<\right.$ 0.05). (D) GJIC inhibition by PKI cell permeable peptide assessed in the calcein dye transfer assay in live IAR20 cells in the absence (top panel) and presence (bottom panel) of 8-CPT-CAMP ( $* * P<0.01$ or *** P<0.005 compared to control; \#\#\# P<0.005 compared to 8-CPT-cAMP-treated).

Fig. 5. Anchored PKA controls $\mathrm{CX} 43$ gap junction intercellular communication. (A) Representative images of a gap-FRAP experiment performed on control IAR20 cells using calcein red-orange AM dye. The bleached region corresponds to a single bleached cell (circled in red). (B) Fluorescence recovery curves for cells treated with 8-CPT-cAMP (30 min) $\pm \mathrm{Ht} 31$ (45 min). Ht31-P peptide was used as a control peptide. Relative intensity of data points is presented as mean \pm SD for at least 10 independent experiments. (C-D) Histograms representing transfer rate constant $k$ calculated for the first 150 seconds (C) and total 600 seconds (D) of the recovery time. ${ }^{*} p<0.05$ for Ctrl vs treatment, ** $p<0.01$ for Ctrl vs treatment, ${ }^{* * *} \mathrm{p}<0.005$ for Ctrl vs treatment; \#\#\# $\mathrm{p}<0.005$ for treatment 1 vs treatment 2 (E) Transfer rate constants for samples treated with disruption peptides specific for the Cx43-Ezrin interaction, $\mathrm{Cx} 43$ wt and $\mathrm{Cx} 43$ mut (peptide with a substitution in the amino acid crucial for the binding). Peptides were applied together with 8-CPT-CAMP. ${ }^{*} p<0.05,{ }^{* *} p<0.01$ (F) Fluorescence recovery curves for $\mathrm{Cx} 43$ and control siRNA transfected cells. Representative western blot and histograms are showing the transfection efficiency. 


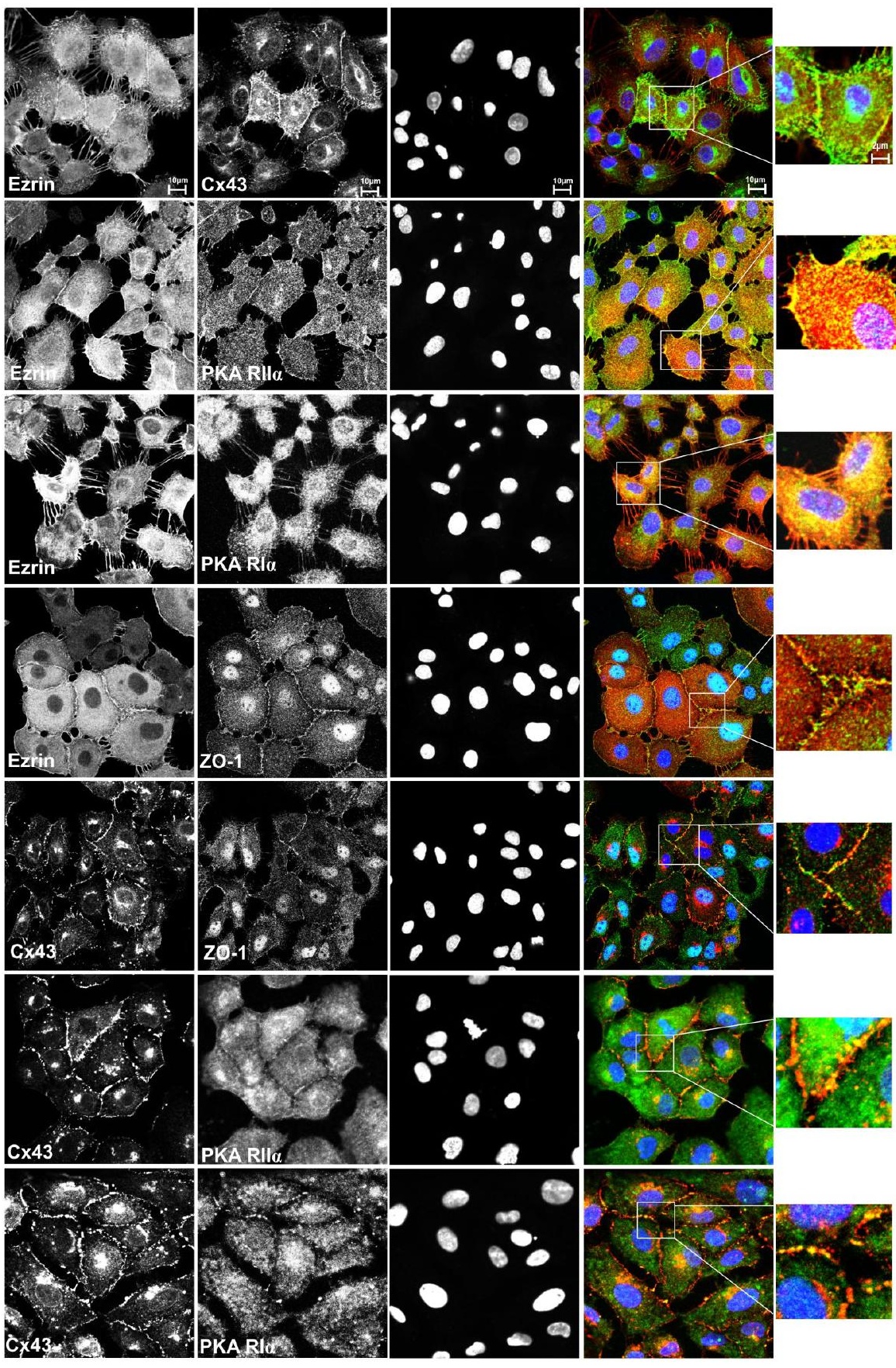




\section{Dukic et al, Figure 2}

A

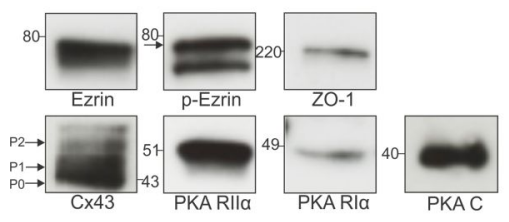

D

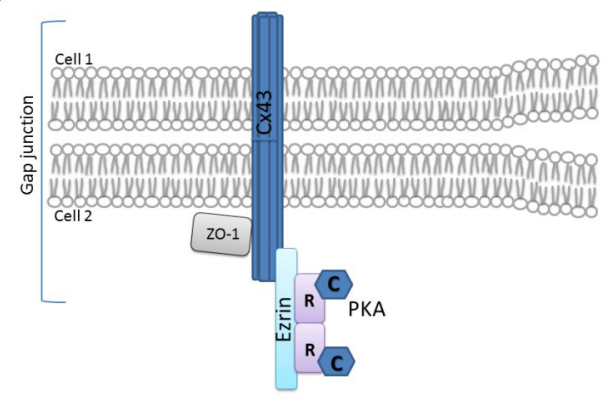

C

CX43 IP
B
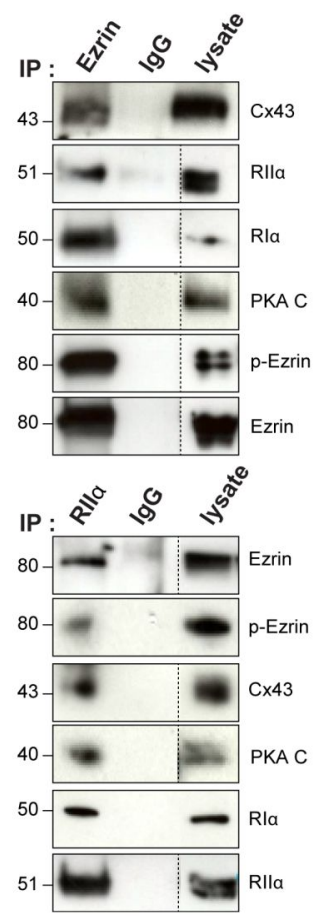
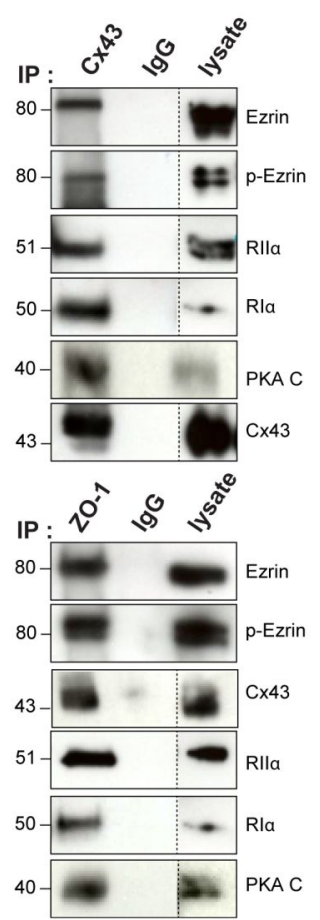

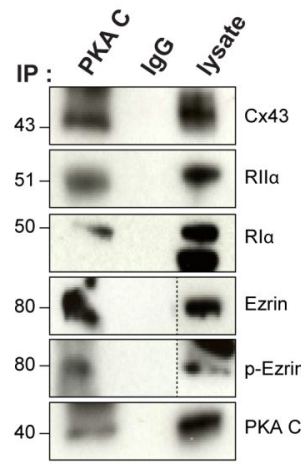

\section{Protein name}

Common name Acc No.

No. of peptides

Confidence

$\mathrm{MW}(\mathrm{kDa})$

Gap junction alpha- 1 protein OS=Rattus norvegicus

cAMP-dependent protein kinase catalytic subunit beta

cAMP-dependent protein kinase type II-alpha regulatory subunit

Ezrin

$\begin{array}{cc}\text { CX43 } & \text { CXA1_RAT } \\ \text { PKA Cb } & \text { KAPCB BRAT } \\ \text { PKA RII } & \text { KAP2_RAT } \\ \text { ezrin } & \text { EZRI RAT }\end{array}$

368
2
2
8

$100 \%$ 
Dukic et al, Figure 3

A
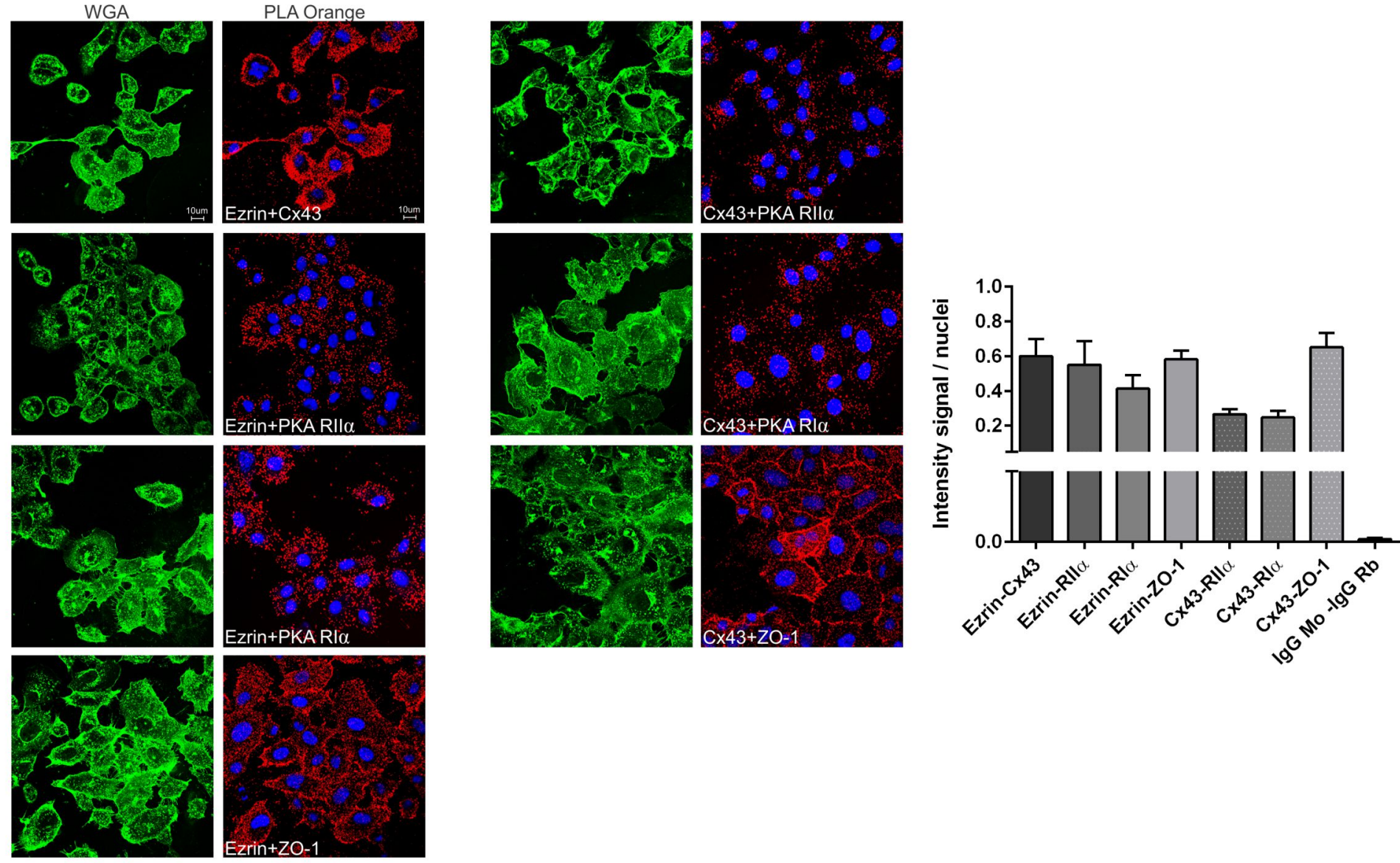

B

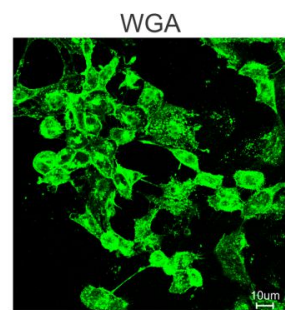

PLA Orange
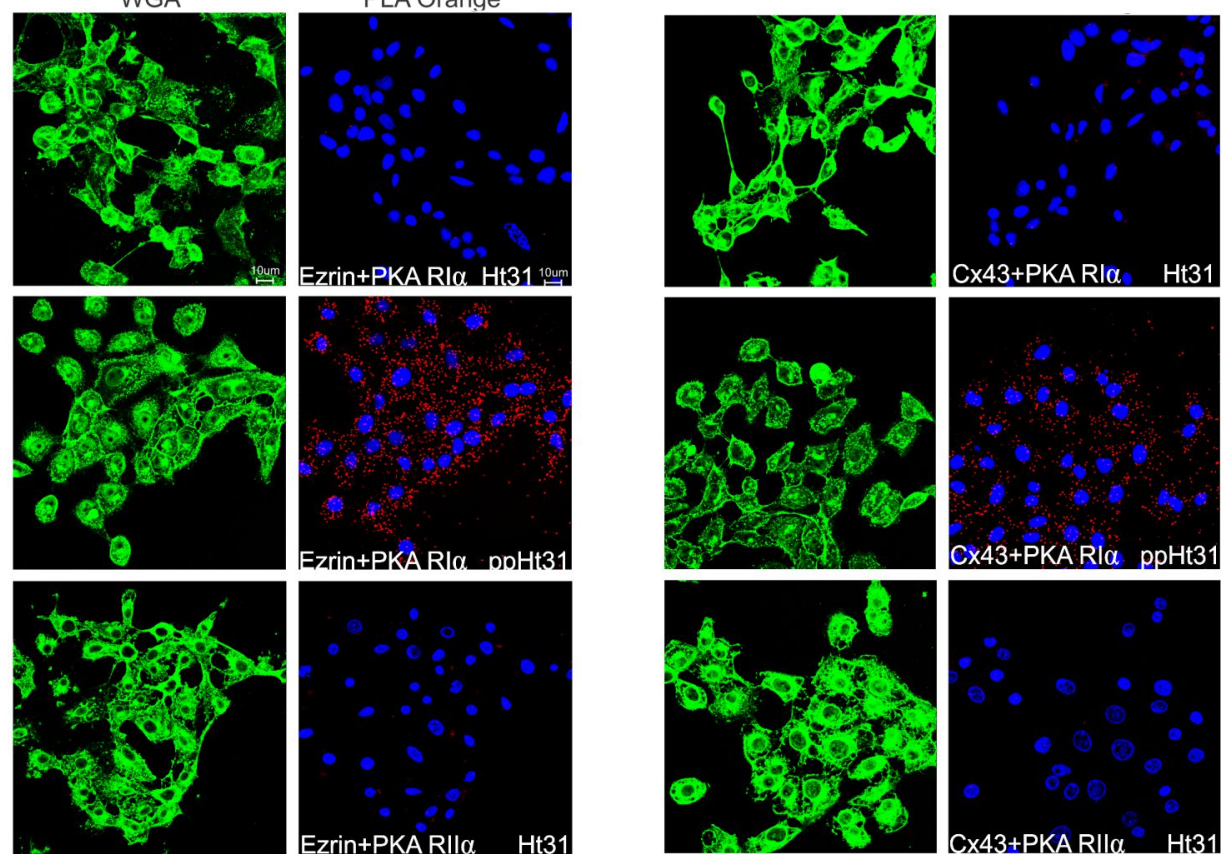

Ezrin+PKARIa noHt31

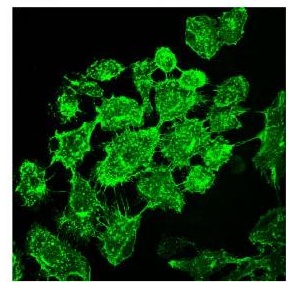

Ezrin+PKARIl $\alpha \quad H+31$

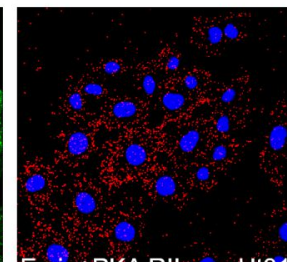

Ezrin+PKA RIl $\alpha$ ppHt31
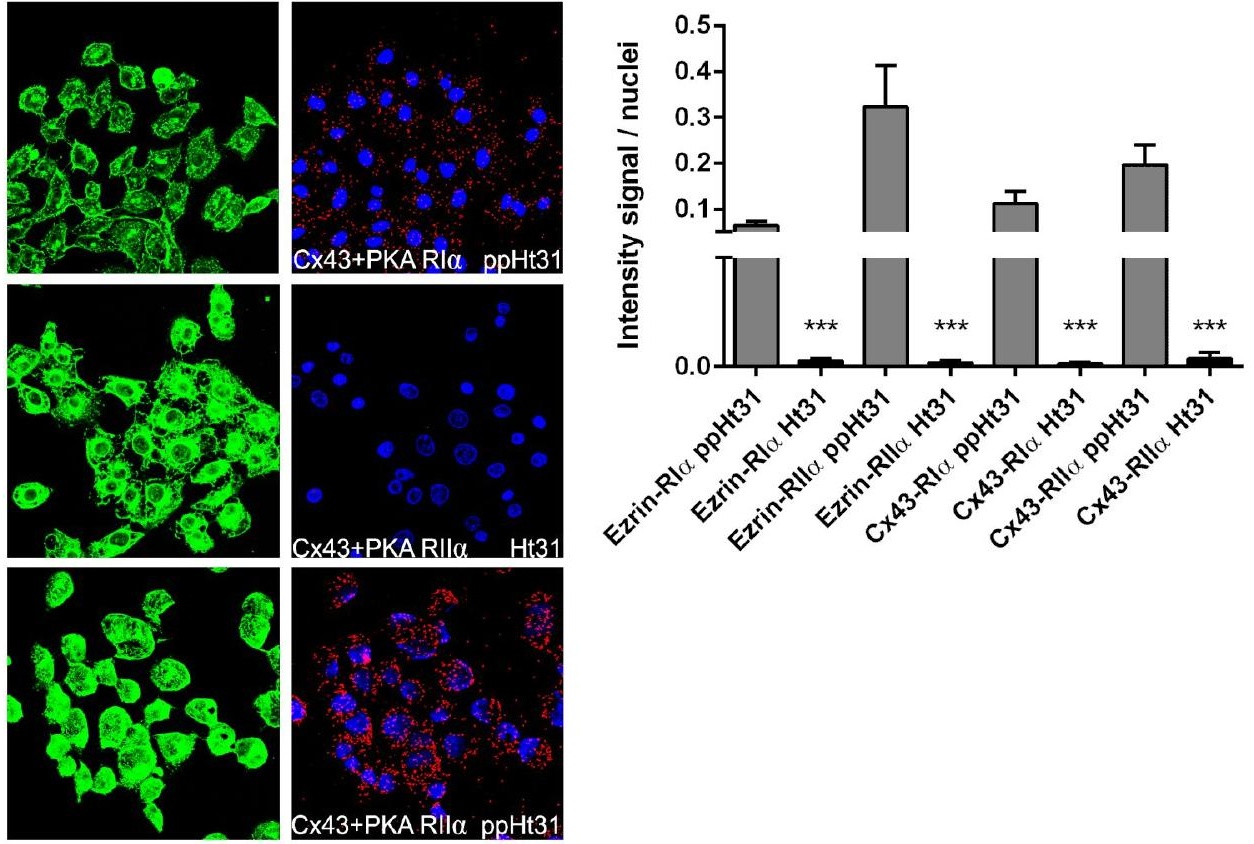
A

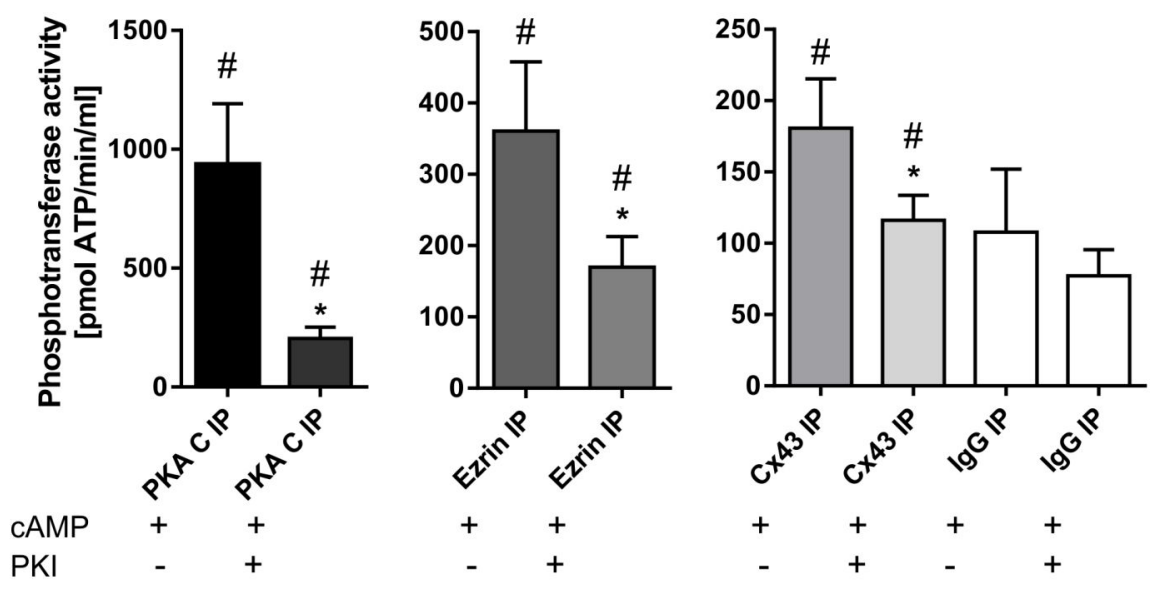

B

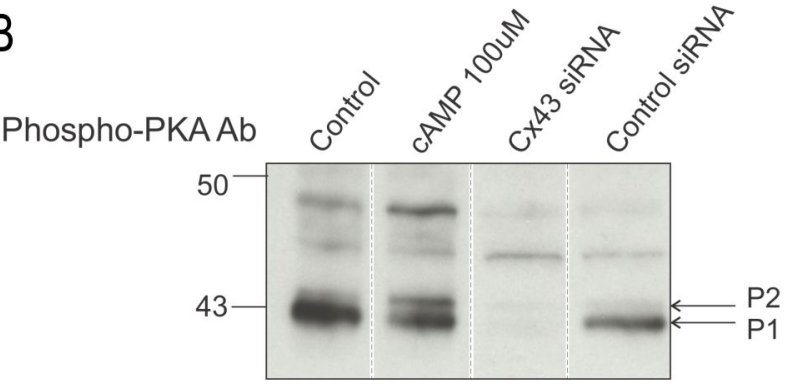

C

D
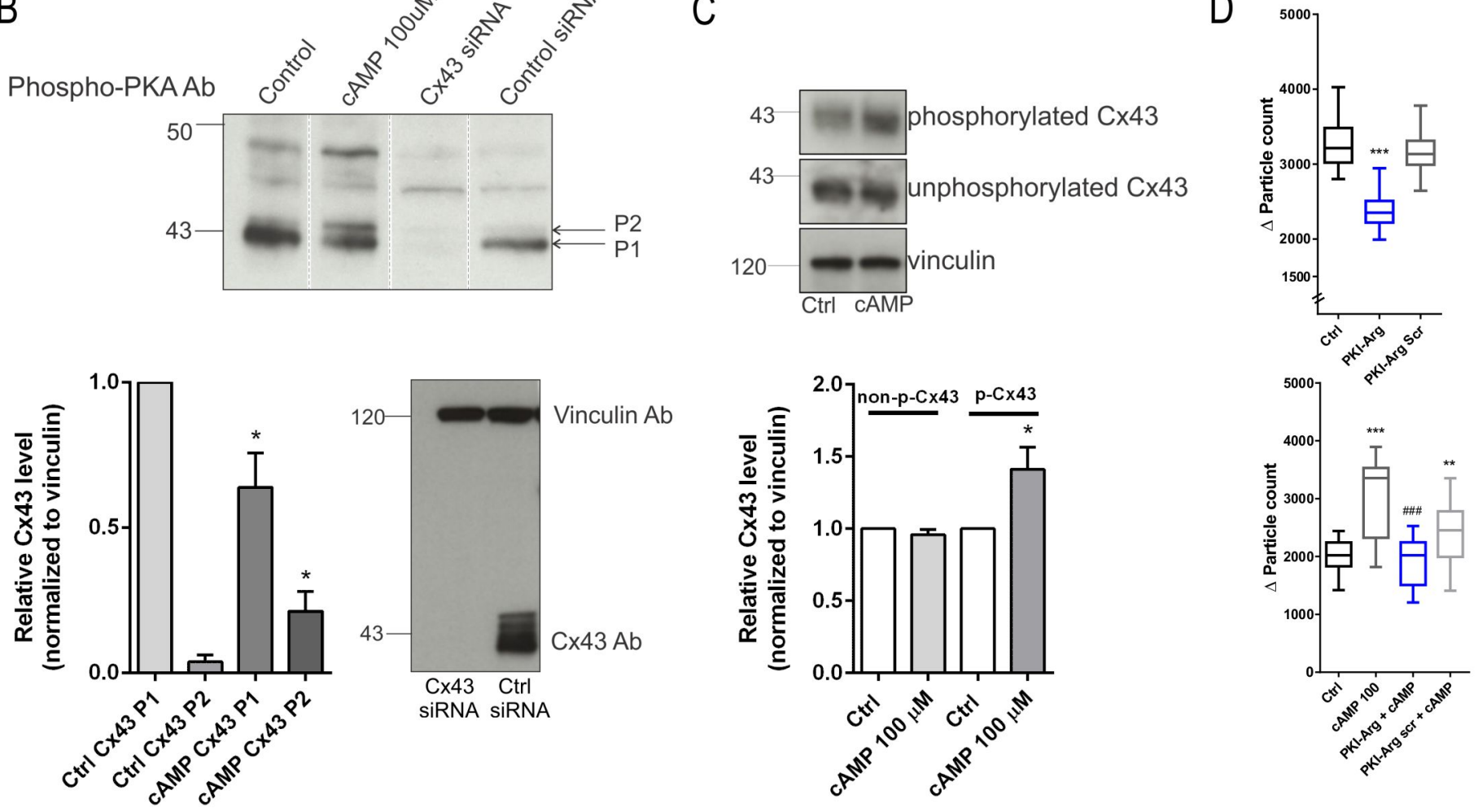
A
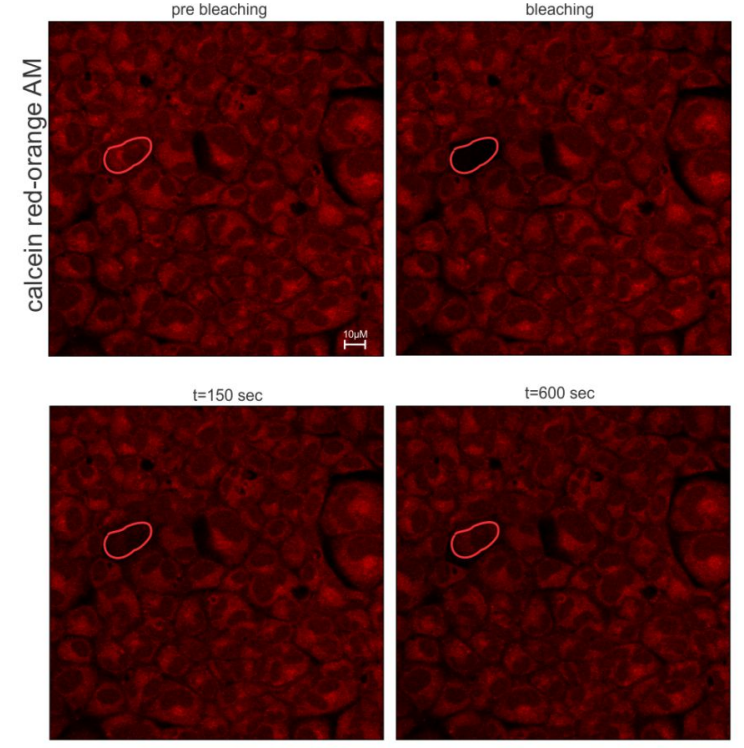

C

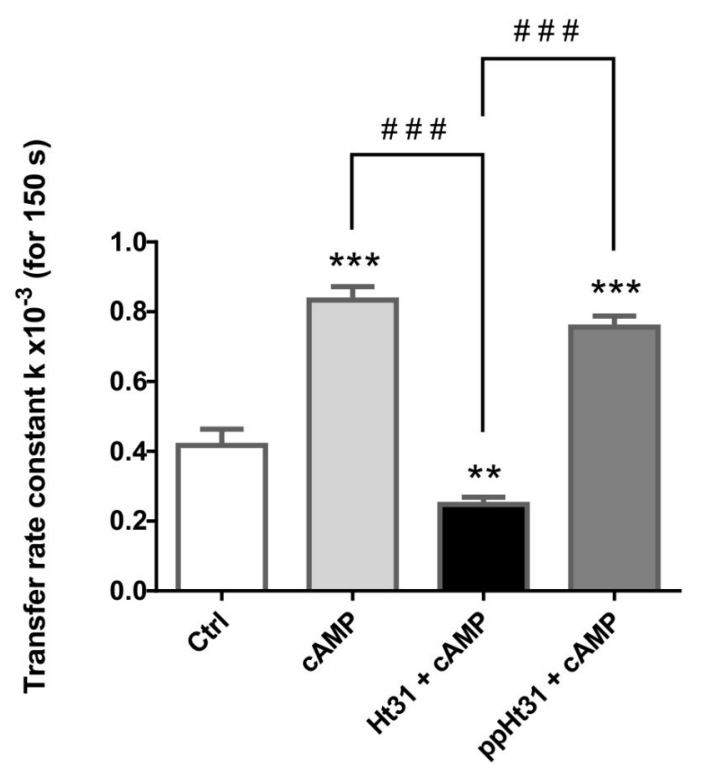

E

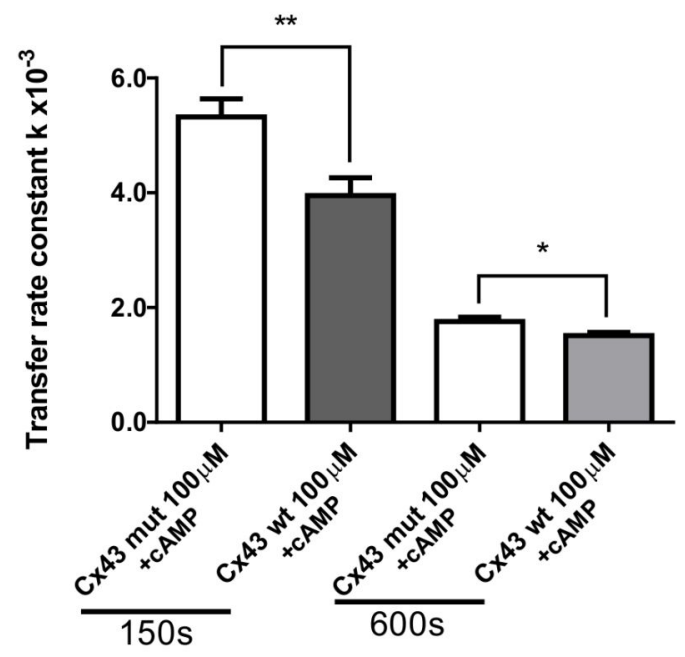

B

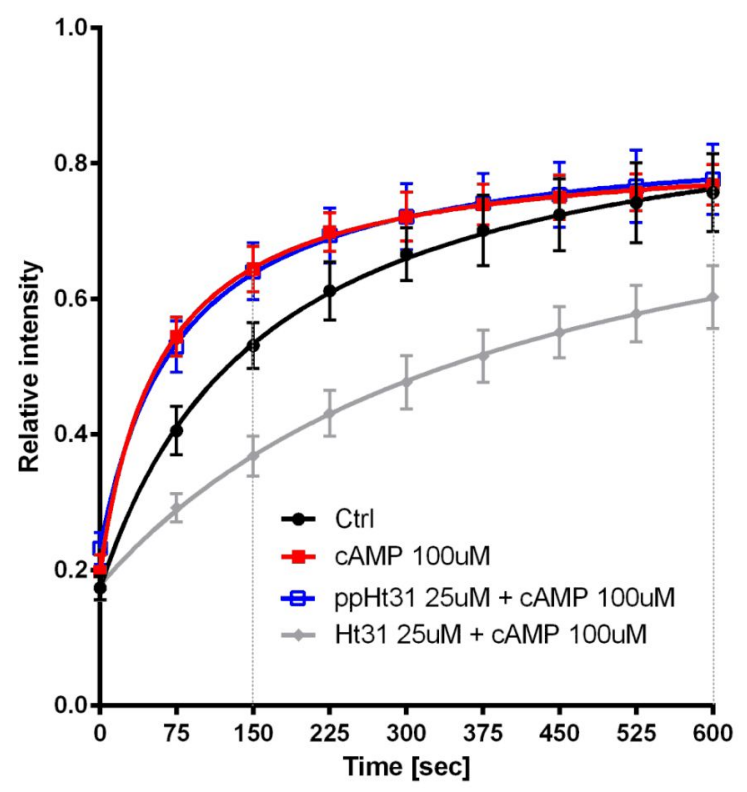

D

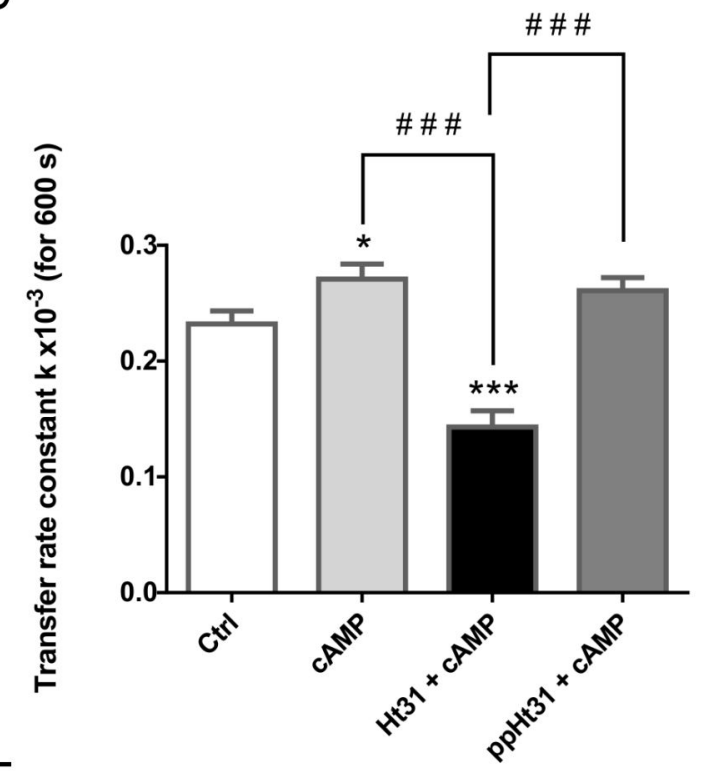

F
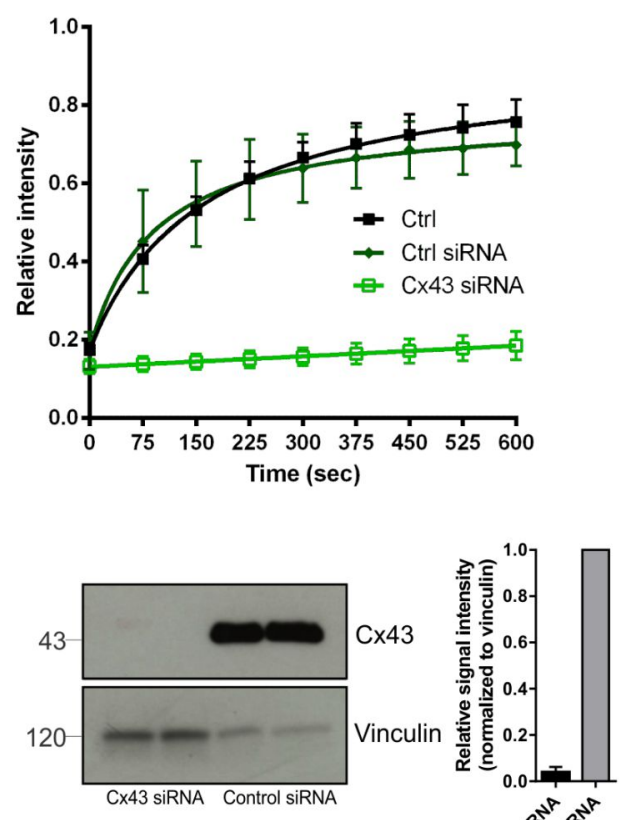